\title{
Econometric Models for Forecasting Remittances of Bangladesh
}

\author{
Tamanna Islam ${ }^{1}$, Ashfaque A. Mohib ${ }^{1} \&$ Shahnaz Zarin Haque ${ }^{1}$ \\ ${ }^{1}$ Department of Operations and Supply Chain Management, Faculty of Business Administration, American International \\ University-Bangladesh, Dhaka, Bangladesh \\ Correspondence: Tamanna Islam, Department of Operations and Supply Chain Management, Faculty of Business \\ Administration, American International University-Bangladesh, Dhaka, Bangladesh.
}

Received: November 8, 2017

Accepted: November 30, 2017

Online Published: December 12, 2017

doi:10.11114/bms.v4i1.2860

URL: https://doi.org/10.11114/bms.v4i1.2860

\begin{abstract}
At present, the remittance of Bangladesh (RB) is the largest source of foreign exchange earning of the country. The RB plays a critical role in alleviating the foreign-exchange constraint and supporting the balance of payments, enabling imports of capital goods and raw materials for industrial development. Remittance from overseas migrant workers certainly increases the income disparity between classes of the rural society. Therefore forecasting plays an important role to know the future situation of economic condition. This paper employed the prospective data on RB to derive a unique and suitable forecasting model. The data were collected from Bangladesh Bank (BB) during January, 1998 to December, 2003. The Autoregressive Integrated Moving Average (ARIMA) and the Generalized Autoregressive Conditional Heteroscedasticity $(\mathrm{GARCH})$ models were used to find out the best one. The findings indicated that the ARIMA $(0,1,1)(0,2,1)_{12}$ and the GARCH $(2,1)$ models were appropriate for our data and the GARCH $(2,1)$ model appeared to be the best one between these.
\end{abstract}

Keywords: autoregressive integrated moving average, generalized autoregressive conditional heteroscedasticity, remittance

\section{Introduction}

People are observing the world considering a large number of alternatives for their better life. Research is the best way to build up such a better life. It is a way of examining the alternative futures and identifying the most probable. Forecasting is also a research in the field of economics. Forecasting is designed to help decision-making and planning in the present for the future. Forecasts are needed continually and the impact of the forecasts on actual performance measure is measured, original forecasts are updated and decisions are modified and so on. Almost all the managerial decisions are based on forecast. Forecasting does not ever finish.

Statistical modeling has the central importance in statistical decision-making, since everything is a model of reality (Abraham \& Johannes, 1983). Despite the importance of the forecasting it is in fact only a representation of reality but not the reality itself. Models cannot be exact to representations. Models show correlation or causation between variables and imply that action is only taken after careful thought and reflections. A heretofore model may lose validity due to changing conditions and may represent inaccurate reality and adversely affecting the ability of the decision-maker to make good decisions. A number of models are suggested for forecasting financing time series data. The problem, the solution expected, types of data, etc. may vary from situation to situation. Therefore, careful attentions as well as valid arguments are needed to select a model for forecasting a financial time series. A particular model may be appropriate for a particular data set e.g. network traffic prediction models use linear time series models such as autoregressive (AR) and autoregressive integrated moving average (ARIMA) model (Sang \& Li, 2002; Adas, 1997).

There are a number of approaches for modeling time series. The AR model is a common approach for modeling univariate time series data. This model can be effectively coupled with moving average (MA) model to form a general and useful class of time series model known as ARMA model. The ARMA model depends on the inputs and the outputs of a system. However, they can only be used for the stationary data set. This class of model can be extended to non-stationary series by allowing differencing of the data series named as ARIMA models (Box \& Jenkins, 1976; Makridakis, Wheelwright, \& Hyndman, 1998). Thus, an ARIMA model is a combination of an AR process and a MA process applied to a non-stationary data series. The use of conditional heteroscedastic model has been a common tool for modeling and forecasting volatility of asset and currency returns following the introduction of the autoregressive 
conditional heteroscedasticity (ARCH) model by Engle $(1982,2004)$ and Bollerslev, Chou, and Kroner (1992) and its generalized version is the generalized autoregressive conditional heteroscedasticity (GARCH) model (Bollerslev, 1986; Engle, 2004).

Remittance is the better instrument to remove poverty (Matin, 1994; Murshid, Iqbal, \& Ahmed, 2001). In recent years, worldwide remittances transfers have increased (Jha, Sugiyarto \& Vargas-Silva, 2009). In developing countries average annual growth rate of remittance flows was 15\%, from 1997 to 2007 (Jha, Sugiyarto \& Vargas-Silva, 2009). In Bangladesh the remittance flow is 10\% of GDP (Jha, Sugiyarto \& Vargas-Silva, 2009). According to recent literature, in Bangladesh, remittance is showing potential contribution to the economic development (Bruyn, 2006). So, it is necessary to pay attention on the future conditions of remittance by using several forecasting models. But all the models do not perform in same way. Therefore, in this paper we compared the forecasting performance of ARIMA and GARCH models in the remittance context of Bangladesh in order to fit the appropriate model.

\section{Method}

\subsection{Data Sources}

The data were collected from the Monthly Economic Trends of Bangladesh Bank (BB) during January, 1998 to December, 2003. This period was selected because the figures against each month were available from the source and there was an opportunity for validation. The forecasting models needed reliable and equally spaced long series of data. Therefore, the monthly remittances were chosen as the variable not only for its availability but also for its originality. Our data set contained 72 observations. The observations were separated into training segment and test segment. The first segment contained first 60 observations and the latter contained the remaining 12 .

\subsection{Model Selection}

The Box-Jenkins (BJ) methodology used to fit an appropriate model for the remittances data (Box \& Jenkins, 1976). This methodology consists of three phases (1) identification, (2) estimation and diagnostic checking and (3) application. It requires at least 40 to 50 equally spaced periods of data. In addition to BJ methodology, Portmanteau tests such as Box-Pierce test (Box \& Pierce, 1970; Grigonytė \& Butkevičiūté, 2016) and Ljung-Box test (Ljung \& Box, 1978) were also used for identifying the stationarity of the data set. These test statistics are asymptotically distributed as chi-square with "h-m" degrees of freedom, where "h" is the maximum lag and " $\mathrm{m}$ " is the number of parameters in the model which has been fitted to the data. The autocorrelation function (ACF) and partial autocorrelations function (PACF) (Makridakis, Wheelwright, and Hyndman, 1998) of the stationary series were observed to see if any pattern remains. The akaike's information criterion (AIC) (Akaike, 1974) was used to select the best model among the plausible models. After identifying a tentative model, we applied the method of maximum likelihood to get preliminary estimates. "R" program was used to refine the estimate. A test of significance of the estimated parameters was done to identify the insignificant estimates (values may have been larger than 0.05). A revised model was considered after omitting the insignificant terms.

Diagnostic checking was done by studying the residuals to verify the model. For a good forecasting model, the residuals left over after fitting the model should be simply white noise. Therefore, we would hope to find no significant autocorrelations and partial autocorrelations in the ACF and PACF of the residuals.

In this study, we considered some well-known measures of forecasting error such as, mean error (ME), mean absolute error (MAE), mean square error (MSE), mean prediction error (MPE), mean absolute percentage error (MAPE), and adjusted mean absolute percentage error (AMAPE) to compare ARIMA and GARCH models. The model that gave the minimum measures of forecast error was our expected model for further forecasting. The ME, MAE and MSE dealt with measures of accuracy and the MPE, MAPE and AMAPE gave the relative comparison.

\section{Results}

The results obtained under the methods mentioned above to find out the suitable model for the considered data set are presented below.

\subsection{Choosing an ARIMA Model}

The time plot of the data showed that, these data had increasing trend (Figure 1). A mathematical transformation is convenient for accounting the increasing variations. Therefore, $\log$ transformation was used to stabilize the variation (Figure 2). To recognize the seasonality we obtained the ACF of the remittances (Figure 3). The pattern was consistent, because the ACF indicated the existence of seasonality. The Box-Pierce and the Ljung-Box test statistics illustrated that the set of correlation values were not significantly different from a null set compared to a chi-square distribution with 24 degrees of freedom. This also indicated that the data set did not follow a white noise series. The obtained data were also non-stationary in mean (Figure 2). So, after $\log$ transformation of the data of the training segment the first 
difference and seasonal second difference ( $t s=$ transferred series) were taken to obtain stability in mean (Figure 4).

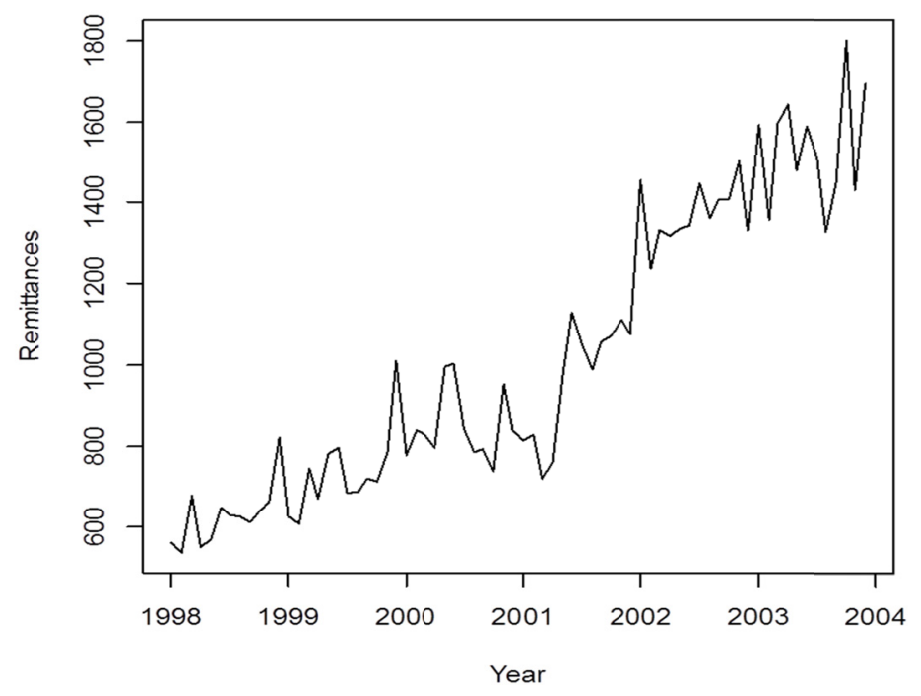

Figure 1. Trend analysis of Remittances (Taka in crores)

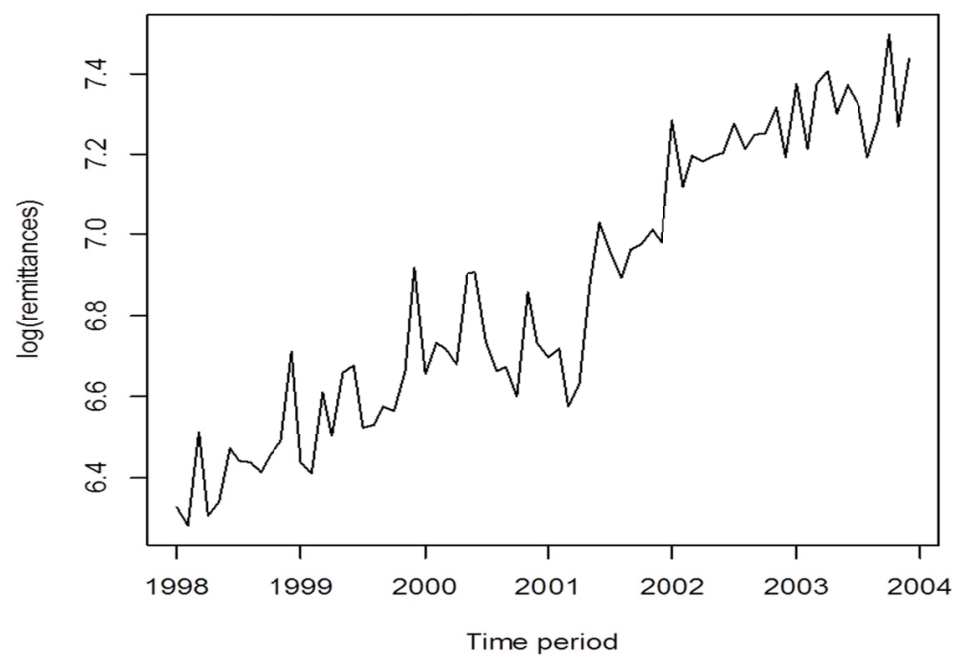

Figure 2. The Time Plot of log Remittances

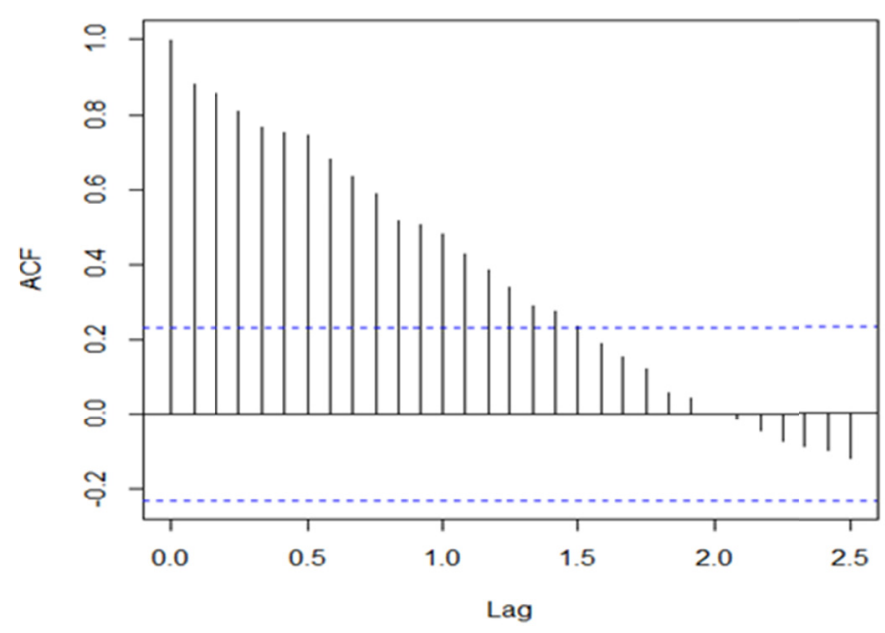

Figure 3. The ACF of Remittances 


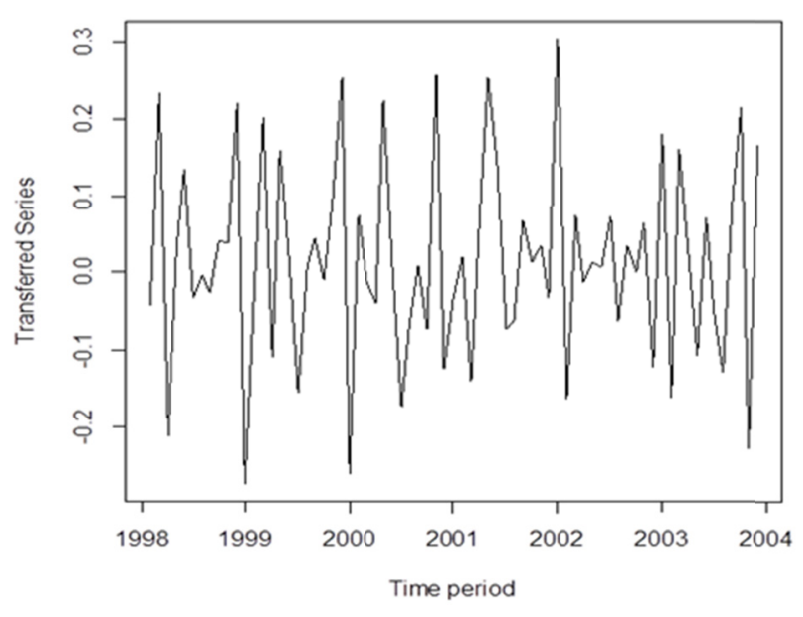

Figure 4. The Time plot of Remittances after Transformation

The time plot of the $t s$ showed that the series was stationary in variance and mean (Figure 4). By using ACF and PACF of the $t s$, it could be said that the series looked like a white noise series with almost no autocorrelations outside the $95 \%$ limits (Figures $5 \mathrm{ab}$ ). The Box-Pierce and the Ljung-Box statistics were equal to 30.7435 and 28.492, respectively. These values were not significant compared to a chi-square distribution with 24 degrees of freedom. The plot of the ACF and PACF (Figures $5 \mathrm{ab}$ ) gave a primary guess about the order of the parameters for ARIMA model.

Selection among ARIMA processes was done and the model with the minimum AIC (R program) was chosen (Table 1). We could not take all the AIC values in Table 1, due to the limitation of computer program to obtain the AIC value by maximizing the likelihood. We found that $\operatorname{ARIMA}(0,1,1)(0,2,1)_{12}$ was the initial model and took the following form
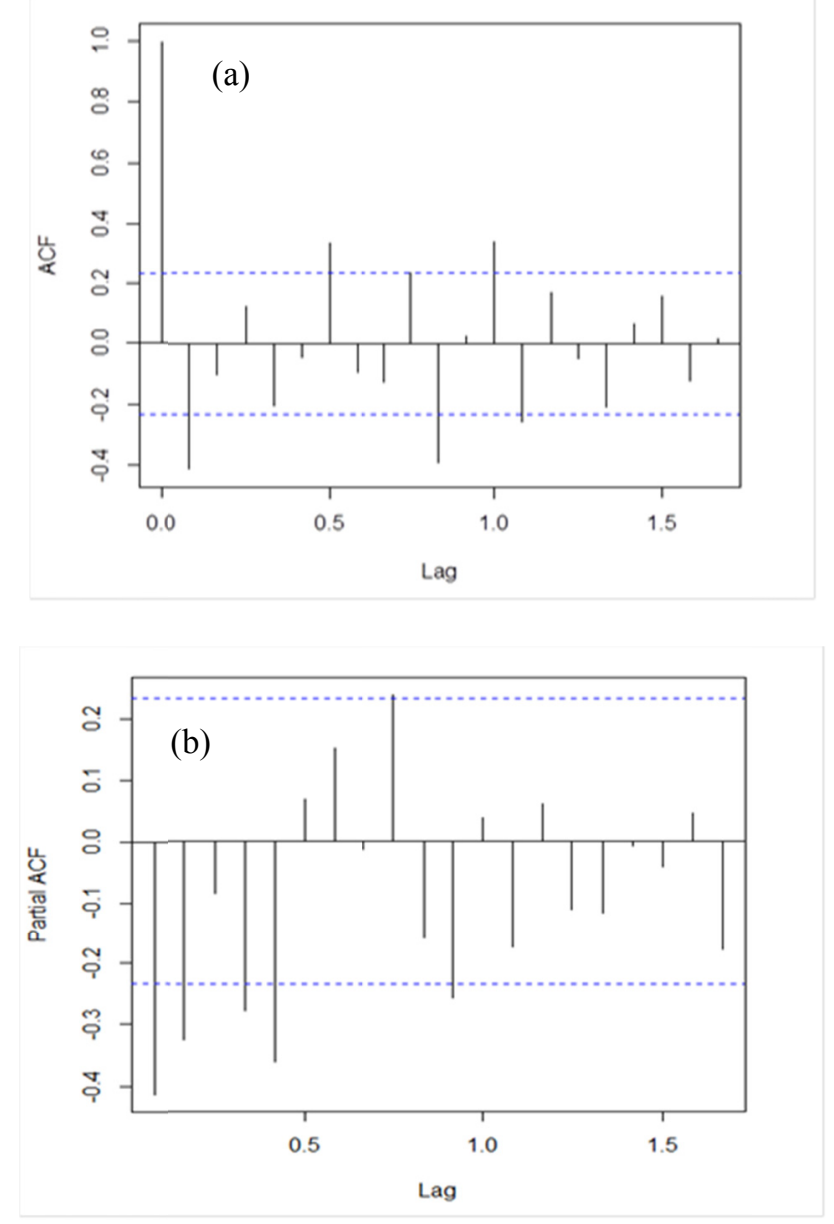

Figure 5. ACF (a) and PACF (b) of log first difference second seasonal differences of Remittances 


$$
(1-B)\left(1-B^{12}\right)^{2} W_{t}=\left(1-\theta_{1} B\right)\left(1-\phi_{1} B^{12}\right) e_{t}
$$

Where $W_{t}=\ln \left(x_{t}\right) \quad$ and

$$
\boldsymbol{X}_{t}=\text { remittance at time } t \text {. }
$$

Table 1. The AIC values for ARIMA model

\begin{tabular}{lcc}
\hline \multicolumn{1}{c}{ Model } & log likelihood & AIC \\
\hline ARIMA $(0,1,1)(0,2,1)_{12}$ & 10.23 & -14.46 \\
ARIMA $(0,1,2)(0,2,1)_{12}$ & 10.23 & -12.45 \\
ARIMA $(1,1,1)(0,2,1)_{12}$ & 10.23 & -12.46 \\
ARIMA $(0,1,1)(1,2,1)_{12}$ & 10.00 & -11.99 \\
ARIMA $(0,1,1)(1,2,2)_{12}$ & 10.46 & -10.91 \\
ARIMA $(0,1,2)(1,2,1)_{12}$ & 10.00 & -10.00 \\
ARIMA $(3,1,1)(1,2,1)_{12}$ & 10.83 & -7.66 \\
ARIMA( $(4,1,1)(1,2,1)_{12}$ & 11.12 & -6.24 \\
\hline
\end{tabular}

AIC (Akaike's Information Criterion); ARIMA (Autoregressive Integrated Moving Average)

Table 2 represents the values of $z$-statistic which were exercised to test the significance of the parameters of initial model.

Table 2. The significance test of the parameters of ARIMA

\begin{tabular}{ccccc}
\hline Coefficients & Parameters & Standard error & z-value & p-value \\
\hline$\theta_{1}$ & -0.3426 & 0.1589 & -2.15 & 0.0158 \\
$\phi_{1}$ & -0.5812 & 0.3160 & -1.839 & 0.0332 \\
\hline
\end{tabular}

ARIMA (Autoregressive Integrated Moving Average)

(a)

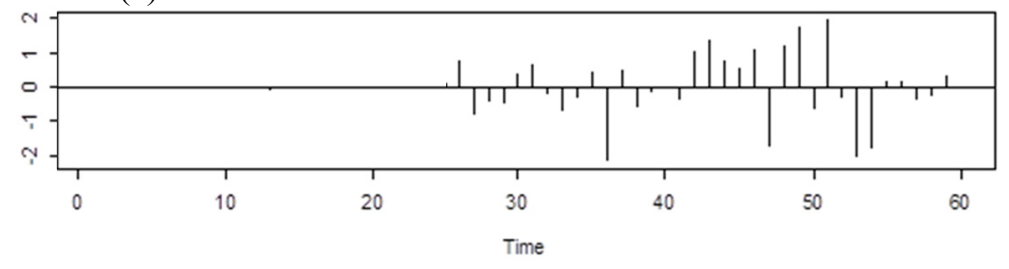

(b)

ACF of Residuals

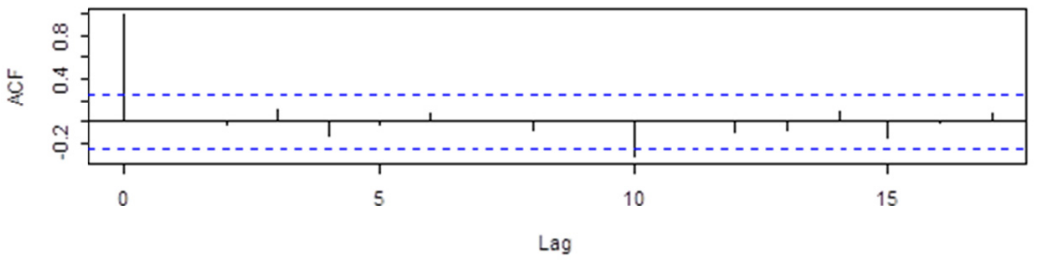

(c)

p values for Ljung-Box statistic

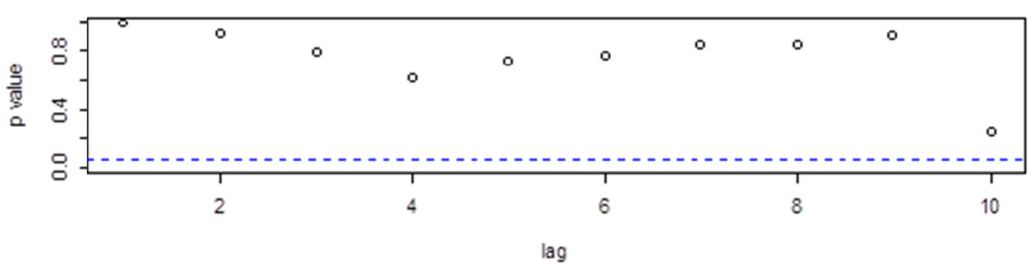

Figure 6. The diagnostic checking of ARIMA $(0,1,1)(0,2,1)_{12}$ model

The $p$-values corresponding to the coefficients demonstrated that the parameters were significant at the $5 \%$ level. Therefore, the estimated model can be expressed as

$$
\hat{x}_{t}=\exp \left(\ln x_{t-1}+2 \ln x_{t-12}-2 \ln x_{t-13}-\ln x_{t-24}+\ln x_{t-25}+0.3426 e_{t-1}+0.5812 e_{t-12}+0.1991 e_{t-13}\right)
$$

Hence, this was the ARIMA model that we selected for forecasting the remittances of Bangladesh. 
Figure 6 focused on the behavior of the residuals after fitting the ARIMA $(0,1,1)(0,2,1)_{12}$ model. The standardized residuals plot showed that, most of the standardized residuals were within the $95 \%$ limits (Figure $6 \mathrm{a}$ ). Almost all of the spikes in the plot of ACF residuals were near to zero and belonged in the $95 \%$ limits (Figure $6 \mathrm{~b}$ ). The plot of $p$-values of the Ljung-Box statistic indicated that the residuals left over after fitting the model were white noise (Figure 6c). All these diagnostic checks supported that the selected model did not have the smallest AIC value only but also the better-behaved residuals. After obtaining the appropriate ARIMA model for forecasting, we used it to forecast the future values in the test set.

\subsection{Choosing a GARCH Model}

Performing the ARCH test, we could say that the main data set had ARCH effect. The Figure 2 and the Ljung-Box test with 24 degrees of freedom for the autocorrelation values indicated that the null hypothesis of no autocorrelation was rejected. Since the data were non-stationary we calculated the return series using the following conversation

$$
y_{t}=\tan \left(100 \times \ln \left(\frac{x_{t}}{x_{t-1}}\right)\right)
$$

After this transformation, the series gave a white noise series with almost no autocorrelations or partial autocorrelations outside the $95 \%$ limits. The ACF at lag1 and the PACF at lag11 were just outside the limits, but it was acceptable to have about $5 \%$ of spikes fall a short distance beyond the limits due to chance (Figure $7 \mathrm{ab}$ ).

The Ljung-Box statistic for these return series compared to a chi-square distribution with 24 degrees of freedom was insignificant. It can be concluded that return series had transformed the data into a white noise series (Figure 8).

The initial model with the minimum AIC was GARCH $(2,1)$ and took the form

$$
\begin{gathered}
Y_{t}=\sigma_{t} \varepsilon_{t} \\
\sigma_{t}^{2}=\alpha_{0}+\alpha_{1} \varepsilon_{t-1}^{2}+\sum_{j=1}^{2} \beta_{j} \sigma_{t-j}^{2}
\end{gathered}
$$

with $\alpha_{0}>0, \alpha, \beta>0$ and $\alpha+\beta<1$. The next step was to test the significance of the parameters. The coefficients with their estimated value and corresponding values of the z-statistics were given in the Table 3 . Table 3 showed that the parameters $\alpha_{0}$ and $\alpha_{1}$ were significant since their p-values of less than 0.05 and the chosen model was a stationary model.

Table 3. The significance test of the parameters of GARCH

\begin{tabular}{lllll}
\hline Coefficients & Parameters & Standard error & z-value & p-value \\
\hline$\alpha_{0}$ & 11.13691 & 2.61835 & 4.253 & $<0.001$ \\
$\alpha_{1}$ & 0.58419 & 0.23091 & 2.530 & 0.0114 \\
$\beta_{1}$ & 0.02237 & 0.06679 & 0.335 & 0.7377 \\
$\beta_{2}$ & 0.08321 & 0.16423 & 0.507 & 0.6125 \\
\hline
\end{tabular}
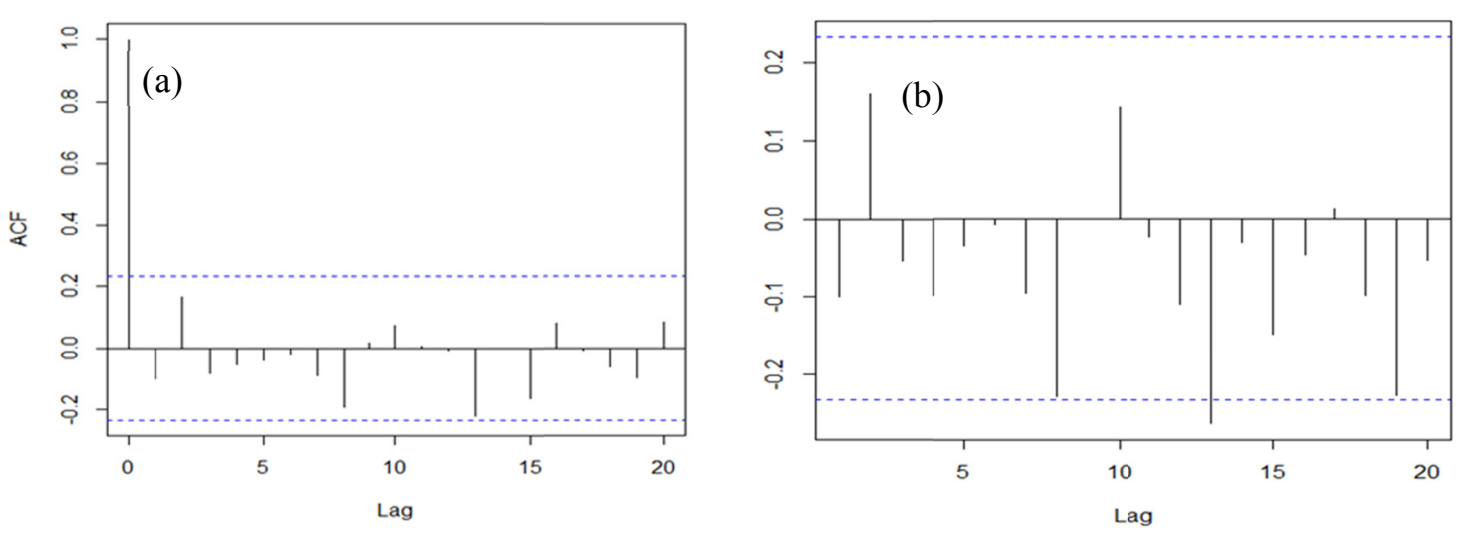

Figure 7. ACF (a) and PACF (b) of return series of Remittances 


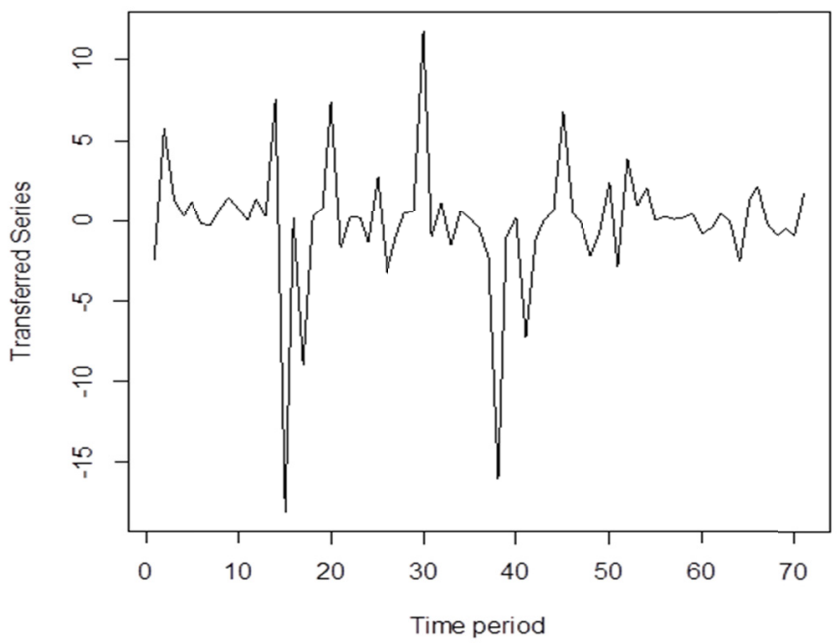

Figure 8. The time plot of transferred series of Remittances

The behavior of the residuals after fitting the GARCH $(2,1)$ model illustrated by the diagnostic checking (Figure 9). The plot of the standardized residuals showed that most of the standardized residuals were belonging within the $95 \%$ limits (Figure 9a). In the plot of ACF almost all of the spikes were in the $95 \%$ limits which were near to zero (Figure 9b). The QQ plot indicated that the residuals after fitting the model were white noise (Figure 9c). Compared to chi-square with 24 degrees of freedom Jarque Bera test represented that the residuals of the return series were non-normal. All these diagnostic check support that our selected model had the smallest AIC value with the better-behaved residuals.

(a)

Residuals

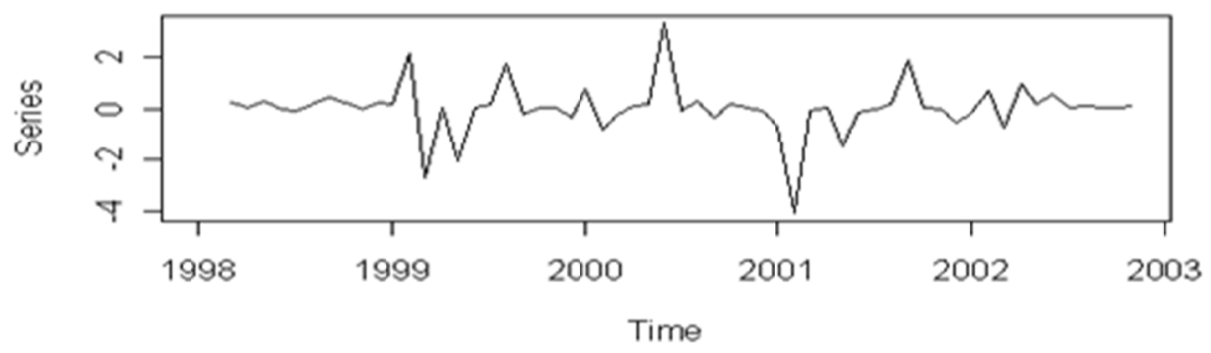

(b)

ACF of Squared Residuals

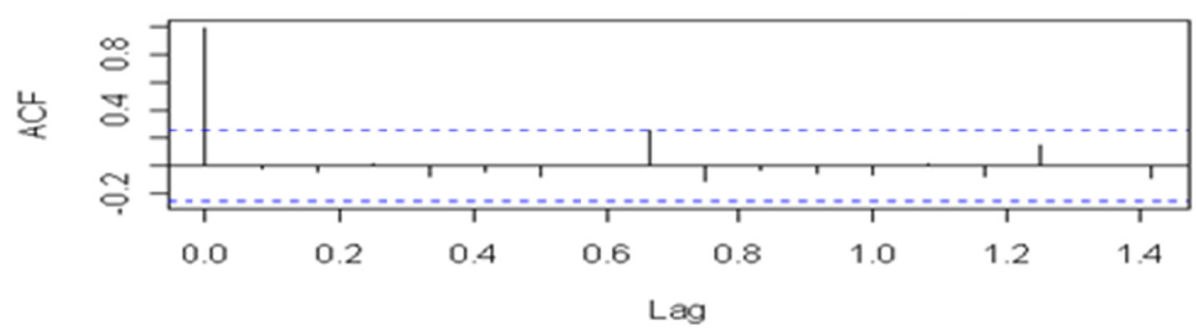

(c) Q-Q Plot of Residuals

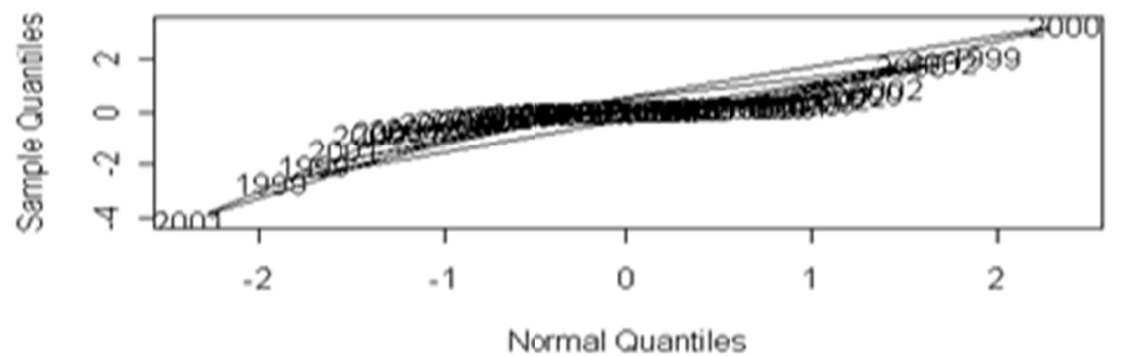

Figure 9. The diagnostic checking of $\operatorname{GARCH}(2,1)$ 


\subsection{Comparison between ARIMA Model and GARCH Model}

The forecasting performance of selected ARIMA model was compared with GARCH model. The forecast errors for each model were obtained by subtracting the forecasted series from the original data series. From these errors different measures of errors were calculated.

Table 4 represented that the GARCH $(2,1)$ model gave the better result over ARIMA $(0,1,1)(0,2,1)_{12}$. Thus it was wise to use the GARCH $(2,1)$ model to forecast the future values of remittances of Bangladesh than that of ARIMA $(0,1,1)$ $(0,2,1)_{12}$ model.

Table 4. Comparison between ARIMA model and GARCH model

\begin{tabular}{lll}
\hline Measures of error & ARIMA & GARCH \\
\hline Mean error (ME) & 2.19 & 0.013 \\
Mean Absolute Error (MAE) & 64.56 & 0.509 \\
Mean Square Error (MSE) & 12135.27 & 0.948 \\
Mean percentage Error (MPE) & 100.04 & 94.998 \\
Mean Absolute percentage Error (MAPE) & 100.04 & 94.998 \\
Adjusted Mean Absolute percentage Error (AMAPE) & 1.02 & 0.949 \\
\hline
\end{tabular}

3.4 Out-of Sample Forecasting During the Period January, 2004 to December, 2004

To see the performance of these two models out-of sample forecasting, we derived the forecasted values of remittances using these two models for the period January, 2004 to December, 2004. The following table gives two forecasted series obtained by the two models as well as the actual data set.

From the Table 5, we could see that the forecasted value for each month in the time period could be obtained by ARIMA $(0,1,1)(0,2,1)_{12}$ and GARCH $(2,1)$ model.

Table 5. The forecasted and actual value of monthly Remittances during the period January, 2004 to December, 2004

\begin{tabular}{llll}
\hline Period & $\begin{array}{l}\text { Remittances } \\
\text { (Taka in crores) }\end{array}$ & $\begin{array}{l}\text { Forecasted value by } \\
\text { ARIMA model }\end{array}$ & $\begin{array}{l}\text { Forecasted value by } \\
\text { GARCH model }\end{array}$ \\
\hline January & 2103.44 & 2627.363 & 1635.801 \\
February & 1509.21 & 2176.577 & 1999.833 \\
March & 1837.51 & 2382.577 & 1535.449 \\
April & 1672.54 & 2369.956 & 1763.682 \\
May & & 2239.239 & \\
June & & 2168.978 & \\
July & & 2464.418 & \\
August & & 2333.626 & \\
September & & 2394.123 & \\
October & & 2397.330 & \\
November & & 2505.000 & \\
December & & 2150.362 & \\
\hline
\end{tabular}

\section{Conclusion}

In this paper an appropriate model was selected for forecasting remittances of Bangladesh. The ARIMA $(0,1,1)(0,2,1)_{12}$ and the GARCH $(2,1)$ model were fitted firstly and then the forecasting performances of these two approaches were compared. Forecasting errors for both the models were obtained and the various measures of forecast errors were calculated. It was found that the GARCH $(2,1)$ gave less average forecasting errors than that of the ARIMA $(0,1,1)$ $(0,2,1)_{12}$ model. This indicated that, in the ARIMA model, the long run variance was considered as constant though for some time period the variance increased significantly. The ARIMA model failed to identify this activity and as a result, over fit by the data in sample tests. However, the GARCH model fitted the data better than the ARIMA model. Evidence for this was that the GARCH model performed better in out-of-sample tests.

It can be concluded that the GARCH modal can be used to forecast the monthly remittances of Bangladesh. Though a good forecasting technique for a situation may not always be a good technique for different a situation. The validation of a particular model must be examined with time changes.

\section{References}

Abraham, B., \& Johannes, L. (1983). Statistical Methods for Forecasting. John Wiley and Sons. https://doi.org/10.1002/9780470316610

Adas, A. (1997). Traffic models in broadband networks. IEEE Communications Magazine, 35(7), 82-89. https://doi.org/10.1109/35.601746 
Akaike, H. (1974). A new look at the statistical model identification. IEEE Transactions on Automatic Control, 19(6), 716-723. https://doi.org/10.1109/TAC.1974.1100705

Bollerslev, T. (1986). Generalized Autoregressive Conditional Heteroskedasticity. Journal of Econometrics, 31, 307-327. https://doi.org/10.1016/0304-4076(86)90063-1

Bollerslev, T., Chou, R. Y., \& Kroner, K. F. (1992). ARCH Modeling in Finance: A Review of the Theory and Empirical Evidence. Journal of Econometrics, 52, 5-60. https://doi.org/10.1016/0304-4076(92)90064-X

Box, G. E. P., \& Jenkins, G. M. (1976). Time Series Analysis Forecasting and Control. San Francisco: Holden-Day.

Box, G. E. P., \& Pierce, D. A. (1970). Distribution of the Autocorrelations in Autoregressive Moving Average Time Series Models. Journal of American Statistical Association, 65, 1509-1526. https://doi.org/10.1080/01621459.1970.10481180

Bruyn, T. D. (2006). Remittances and Expatriates: Development in Bangladesh. Organised by the Bangladesh Support Group (BASUG), 22 April 2006, Golden Tulip (Bel Air Hotel), The Hague. http://citeseerx.ist.psu.edu/viewdoc/download?doi=10.1.1.659.3098\&rep=rep1\&type=pdf

Engle, R. (1982). Autoregressive Conditional Heteroskedasticity with Estimates of the Variance of United Kingdom Inflation. Econometrica, 50, 987-1007. https://doi.org/10.2307/1912773

Engle, R. (2004). Risk and Volatility: Econometric Models and Financial Practice. The American Economic Review, 94, 405-420. https://doi.org/10.1257/0002828041464597

Grigonyte, E., \& Butkevičiūtè, E. (2016). Short-term wind speed forecasting using ARIMA model. Energetika, 62, 45-55. https://doi.org/10.6001/energetika.v62i1-2.3313

Jha, S., Sugiyarto, G., \& Vargas, S. C. (2009). The Global Crisis and the Impact on Remittances to Developing Asia. ADB Economics Working Paper Series 185. https://doi.org/10.2139/ssrn.1618088

Ljung, G. M., \& Box, G. E. P. (1978). On a measure of lack of fit in time series models. Biometrika, 65, 297-303. https://doi.org/10.1093/biomet/65.2.297

Makridakis, S. G., Wheelwright, S. C., \& Hyndman, R. J. (1998). Forecasting: Methods and Applications (3rd ed.). New York: John Riley and Sons.

Matin, A. K. (1994). The overseas Migrant Workers, Remittances and the Economy of Bangladesh: 1976/77 to 1992/93. Journal of Business Studies, 15, 87-109.

Murshid, K. A. S., Iqbal, K., \& Ahmed, M. (2001). Migrant Workers from Bangladesh Remittance Inflows and Utilization. Research Report.

Sang, A., \& Li, S. (2002). A predictability analysis of network traffic. Computer networks, 39, 329-345. https://doi.org/10.1016/S1389-1286(01)00304-8

\section{Copyrights}

Copyright for this article is retained by the author(s), with first publication rights granted to the journal.

This is an open-access article distributed under the terms and conditions of the Creative Commons Attribution license which permits unrestricted use, distribution, and reproduction in any medium, provided the original work is properly cited. 